\title{
PEMANFAATAN TEKNOLOGI INFORMASI BERUPA WEB BASED APPLICATION PADA SEKTOR USAHA KECIL DAN MENENGAH
}

\author{
Ahmad Sanmorino1) \\ 1)Program Studi Sistem Informasi Universitas Indo Global Mandiri \\ Jl. Jend Sudirman No.629 Km.4 Palembang Kode pos 30129 \\ Email : sanmorino@uigm.ac.id ${ }^{1)}$
}

\begin{abstract}
ABSTRAK
Perkembangan dibidang teknologi dan ilmu pengetahuan membuat sektor usah harus semakin peka dalam peningkatan kualitas sumber daya yang dimilikinya. Oleh karena itu untuk menyikapi fenomena tersebut perlu adanya tindak lanjut dari perusahaan sebagai upaya agar kemampuan yang dimiliki karyawannya tidak statis akan tetapi berkembang secara dinamis. Salah satunya dengan pemanfaatan teknologi informasi berupa aplikasi berbasis web. Langkah awal pemanfaatan teknologi informasi ini bisa dimulai dengan pemberian pelatihan penggunaan aplikasi kepada para karyawan suatu perusahaan. Adapun yang menjadi tempat pelatihan pemanfaatan teknologi informasi pada kegiatan pengabdian masyarakat ini adalah sektor usaha kecil dan menengah yaitu perusahaan air bersih di Kelurahan Muara Dua Kota Prabumulih. Kegiatan pelatihan ini menjelaskan tentang manfaat penggunaan aplikasi pengolahan data berbasis web pada bidang usaha air bersih. Tujuan kegiatan ini adalah memberikan pemahaman kepada para pekerja pada usaha air bersih di Kelurahan Muara Dua Kota Prabumulih tentang pemanfaatan aplikasi pengolahan data berbasis web untuk meningkatkan produktivitas dan efisiensi pengolahan air bersih. Berdasarkan pelatihan yang telah dilakukan, para pekerja sangat antusias dan tertarik untuk segera memanfaatkan teknologi informasi.
\end{abstract}

Kata kunci : Pemanfaatan, Teknologi Informasi, Sektor Usaha

\section{PENDAHULUAN}

Saat ini pemanfaatan teknologi informasi hampir meliputi semua bidang kehidupan, seperti bidang pendidikan, kesehatan, bisnis dan manajemen, pertanian dan peternakan, penambangan, pertahanan dan keamanan serta bidang transportasi. Pada bidang pendidikan contohnya seperti yang dilakukan oleh beberapa peneliti, dengan membuat perangkat bantu sehingga proses belajar mengajar menjadi lebih interaktif dan efektif. Dalam bidang keamanan teknologi informasi dapat digunakan untuk pelbagai jenis keperluan. Di era internet saat ini, kejahatan dunia maya atau cyber crime semakin meningkat salah satunya dengan melakukan serangan terhadap server yang memberikan layanan terhadap masyarakat. Dengan kemajuan teknologi informasi hal ini dapat dicegah atau dihindari. Pemanfaatan teknologi informasi yang lain diantaranya verifikasi pengesahan suatu dokumen, hal ini penting dilakukan supaya tidak terjadi pemalsuan dan pencatutan nama seseorang. Pemanfaatan teknologi informasi juga dapat digunakan untuk memajukan produk lokal seperti memfasilitasi informasi tentang batik di web, supaya siapapun yang mencari atau memasukan kata kunci batik dapat menemukannya dengan mudah dan cepat. Dalam bidang peternakan, teknologi informasi dapat digunakan untuk pengelolaan data peternakan supaya proses data dapat berjalan lebih baik, lebih cepat dan minim kesalahan. Dalam bidang farmasi, teknologi informasi dapat digunakan untuk pengelolaan penyimpanan obat, meminimalkan waktu dan memaksimalkan proses input-output obat dari gudang.

Pada kegiatan ini kami mencoba memberikan andil pemanfaatan teknologi informasi pada bidang usaha kecil dan menengah yaitu usaha air bersih di Kelurahan Muara Dua, Kota Prabumulih. Adapun bentuk kegiatan yang akan dilakukan adalah memberikan penjelasan kepada pekerja dan pemilik usaha tentang pemanfaatan aplikasi pengelolaan data berbasis web, kemudian dilanjutkan dengan memberikan pelatihan pemanfaatan aplikasi pengolahan data berbasis web pada usaha air bersih di Kelurahan Muara Dua, Kota Prabumulih. 


\section{METODE PELAKSANAAN PENGABDIAN}

Pelaksanaan pengabdian masyarakat dilakukan dengan memberikan penjelasan dan pelatihan pemanfaatan teknologi informasi berupa aplikasi pengolahan data berbasis web pada usaha air bersih di Kelurahan Muara Dua, Kota Prabumulih. Adapun rincian kegiatan yang meliputi waktu, jadwal dan peserta diuraikan sebagai berikut:

\subsection{Waktu Kegiatan}

Sebelum kegiatan pengabdian pada masyarakat dilakukan perlu adanya persiapan yang harus dilakukan terlebih dahulu yaitu:

1) Merencanakan kegiatan pengabdian masyarakat dan memastikan dapat diterima oleh pemilik Usaha Air Bersih di Kelurahan Muara Dua Kota Prabumulih.

2) Menetapkan hari, tanggal kegiatan, tempat serta peralatan yang perlu dipersiapkan untuk pelaksanaan kegiatan pelatihan tersebut.

3) Mengajukan rencana kegiatan pengabdian masyarakat kepada Ketua LP2MK Universitas Indo Global Mandiri.

4) Mempersiapkan bahan/materi pelatihan dalam bentuk handout yang akan dibagikan kepada pemilik dan para pekerja sebagai peserta pelatihan.

5) Mempersiapkan feedback dan evaluasi pelatihan dalam bentuk kuesioner yang akan dibagikan kepada pemilik dan para pekerja sebagai peserta pelatihan.

6) Setelah persiapan selesai, ditetapkan waktu kegiatan pengabdian kepada masyarakat.

\subsection{Peserta Kegiatan}

Diikuti oleh pemilik dan para pekerja pada Usaha Air Bersih di Kelurahan Muara Dua Kota Prabumulih.

\subsection{Jadwal Kegiatan}

Adapun jadwal kegiatan pengabdian masyarakat "Pemanfaatan Teknologi Informasi Berupa Web Based Application Pada Sektor Usaha Kecil Dan Menengah" adalah sebagai berikut:

Tabel 1. Jadwal Kegiatan

\begin{tabular}{|c|c|}
\hline & \\
\hline MATERI & FASILITATOR \\
\hline Senin, 26 Desember 2016 & \\
\hline $\begin{array}{l}\text { 1. Tatap muka tim PPM UIGM dengan } \\
\text { pemilik dan pekerja usaha air bersih, } \\
\text { 2. Memaparkan maksud dan tujuan } \\
\text { kedatangan tim PPM UIGM, } \\
\text { 3. Technical Meeting }\end{array}$ & $\begin{array}{l}\text { Pemilik Usaha Air Bersih dan } \\
\text { Peternakan 'Maju Bersama’ dan } \\
\text { Ahmad Sanmorino }\end{array}$ \\
\hline Selasa, 27 Desember 2016 & \\
\hline $\begin{array}{l}\text { 1. Pemaparan tujuan dan manfaat } \\
\text { penggunaan aplikasi pengolahan data } \\
\text { berbasis web oleh Ahmad Sanmorino, } \\
\text { 2. Pengisian kuesioner pelatihan oleh } \\
\text { Peserta Pelatihan }\end{array}$ & Ahmad Sanmorino \\
\hline Rabu, 28 Desember 2016 & \\
\hline $\begin{array}{l}\text { 1. Pemaparan contoh Aplikasi dan Fitur yang } \\
\text { disediakan oleh Narasumber, } \\
\text { 2. Pengisian kuesioner pelatihan oleh } \\
\text { Peserta }\end{array}$ & Ahmad Sanmorino \\
\hline
\end{tabular}




\section{HASIL DAN PEMBAHASAN}

Pemahaman pemanfaatan aplikasi pengolah data berbasis web bagi usaha air bersih, dapat meningkatkan produktivitas kinerja dengan memanfaatkan teknologi Informasi. Kemampuan penggunaan aplikasi pengolah data berbasis web bagi usaha air bersih dan pemeliharaannya untuk berbagai keperluan dapat dipergunakan oleh para pekerja untuk keperluan diluar dari kepentingan usaha. Dengan pengetahuan dasar penggunaan komputer yang baik, diharapkan para pekerja Usaha Air Bersih di Kelurahan Muara Dua Kota Prabumulih khususnya, dapat mengembangkan ilmu yang didapat selama pelatihan. Dapat membantu Usaha Air Bersih di Kelurahan Muara Dua Kota Prabumulih semakin maju dan berkembang dikarenakan meningkatnya keahlian dan keterampilan yang dimiliki oleh para pekerja.

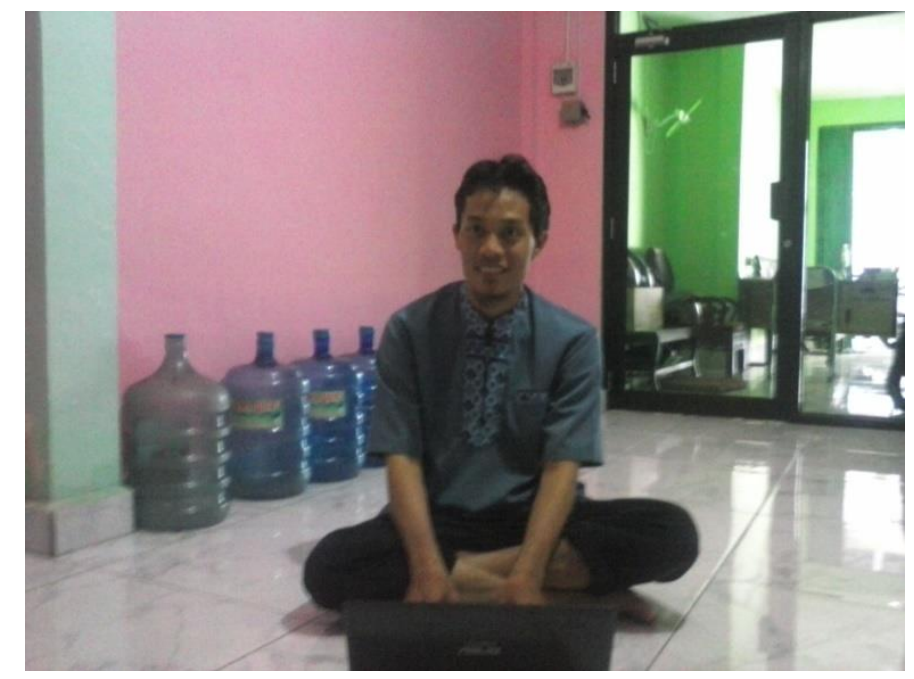

Gambar 1. Pelatihan Pemanfaatan Aplikasi Pengolahan Data berbasis Web pada Usaha Air Bersih

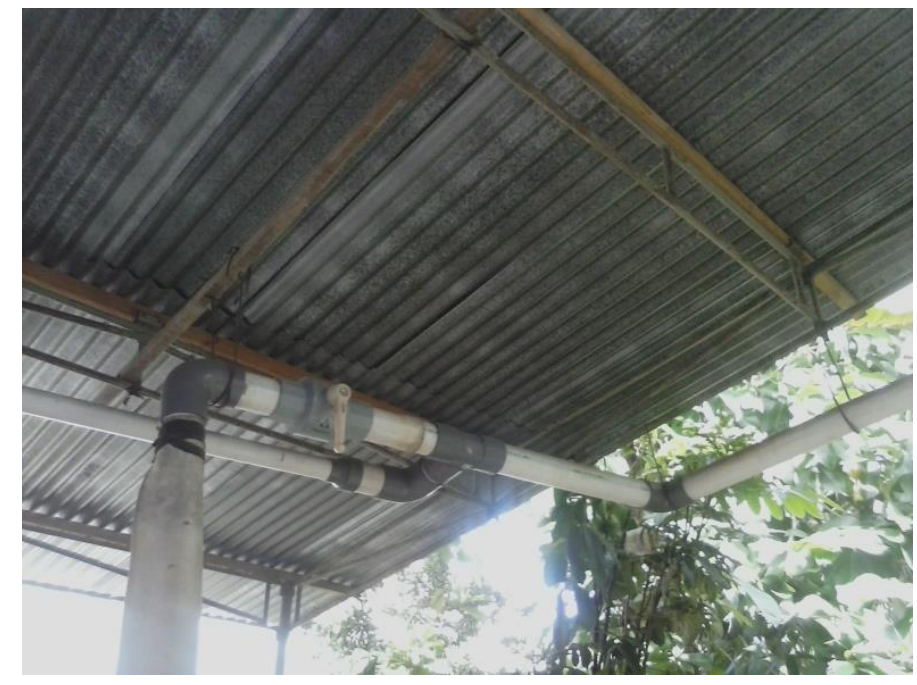

Gambar 2. Instalasi Penyaluran Air Bersih 


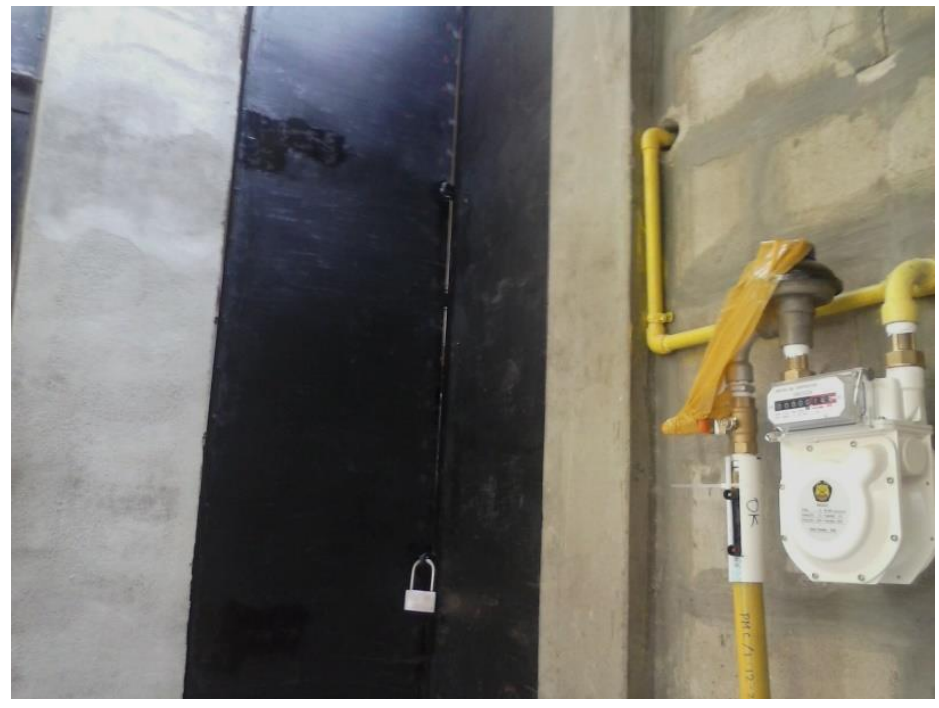

Gambar 3. Instalasi Penyaluran Air Bersih

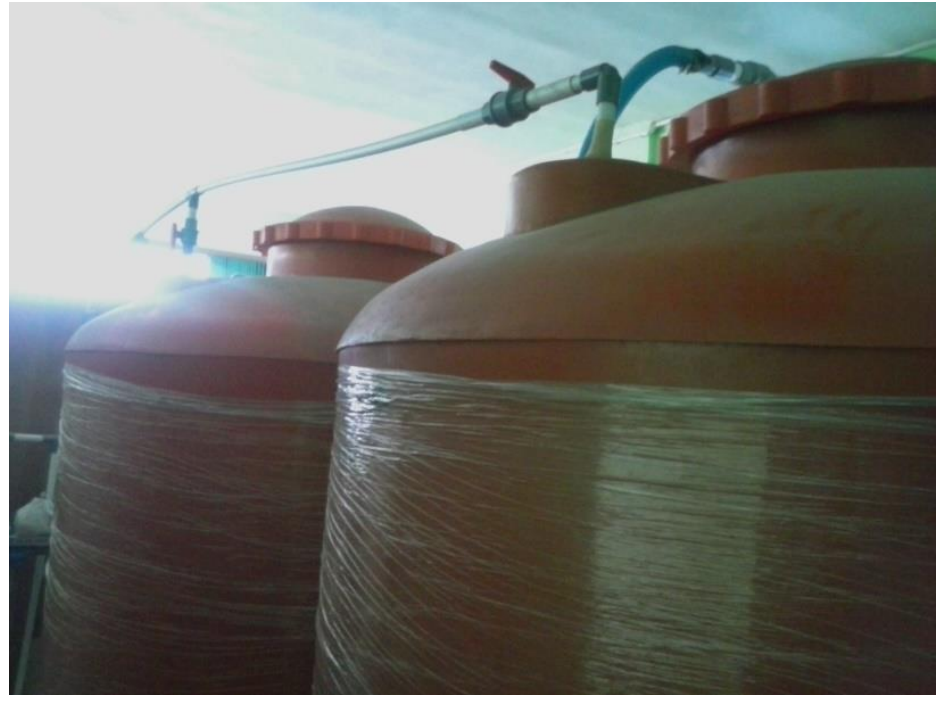

Gambar 4. Tempat Penampungan Air Bersih

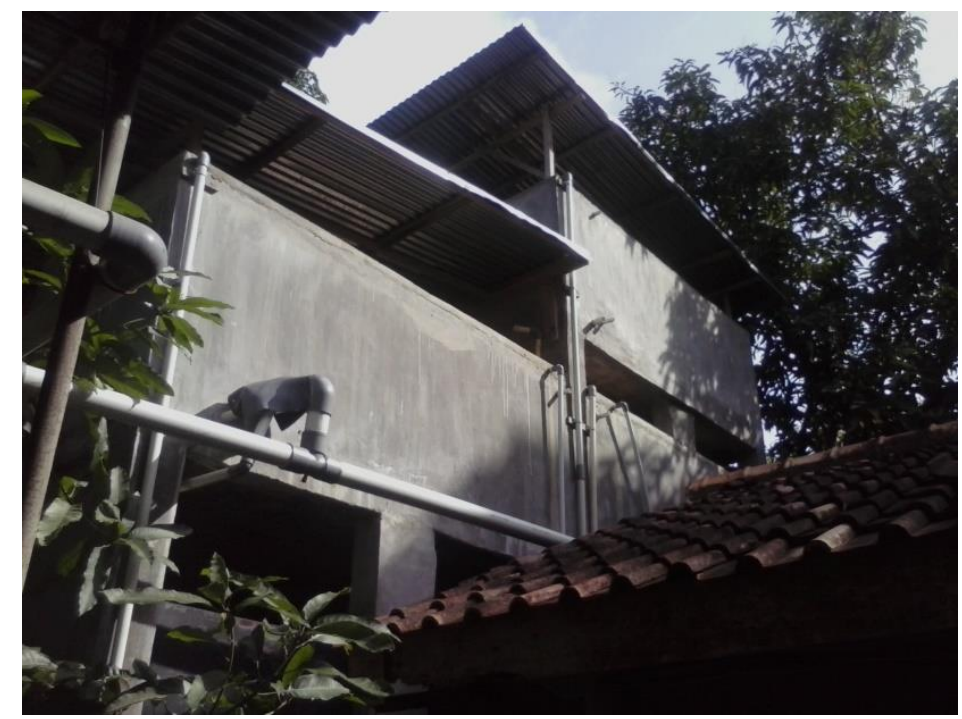

Gambar 5. Tempat Penampungan Air Bersih 
Adapun contoh tampilan dari aplikasi pengelolaan air besih yang kami gunakan didalam pelatihan adalah sebagai berikut:

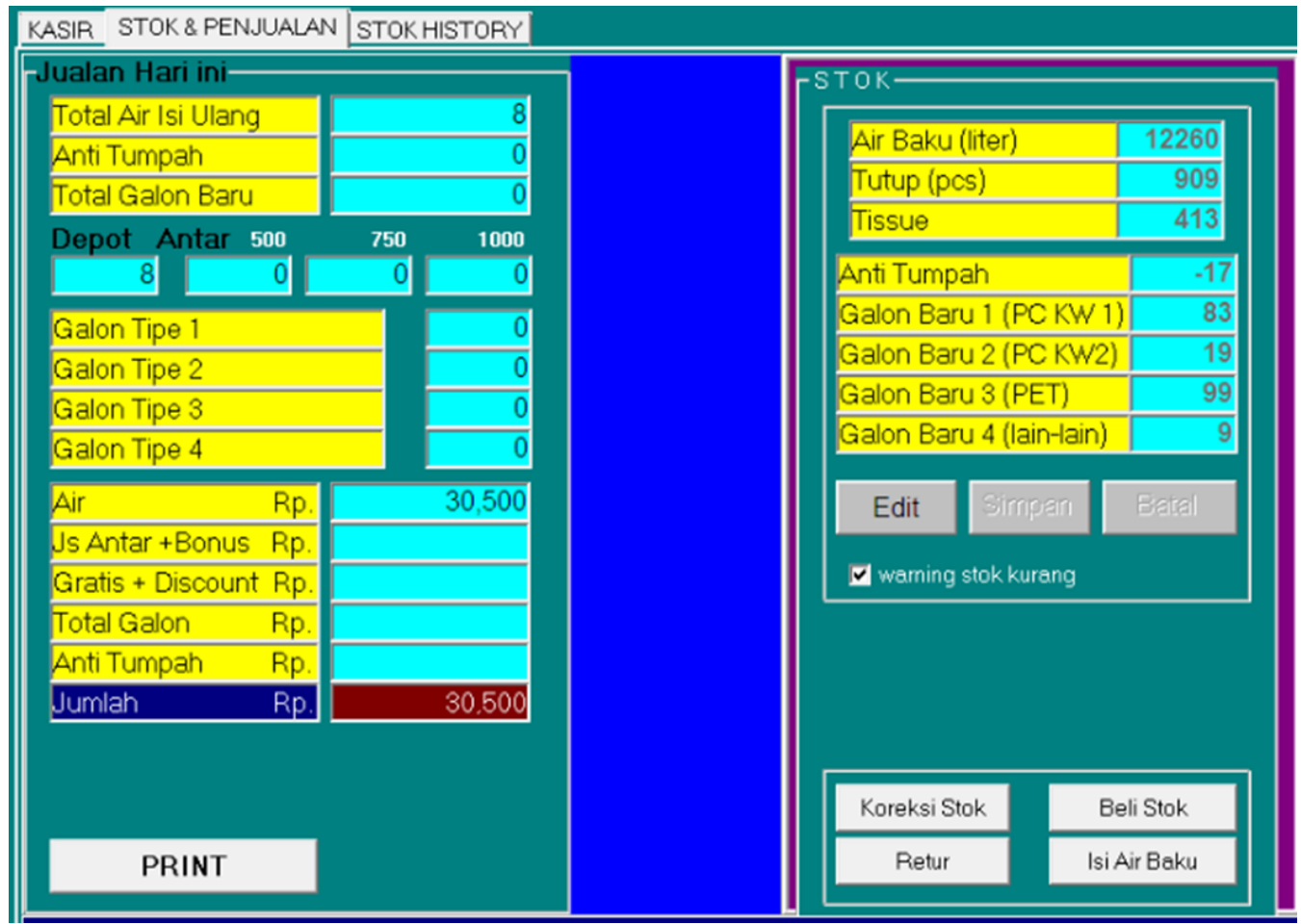

Sumber: http://beningsoft.com

Gambar 6. Contoh Aplikasi Pengelolaan Air Bersih

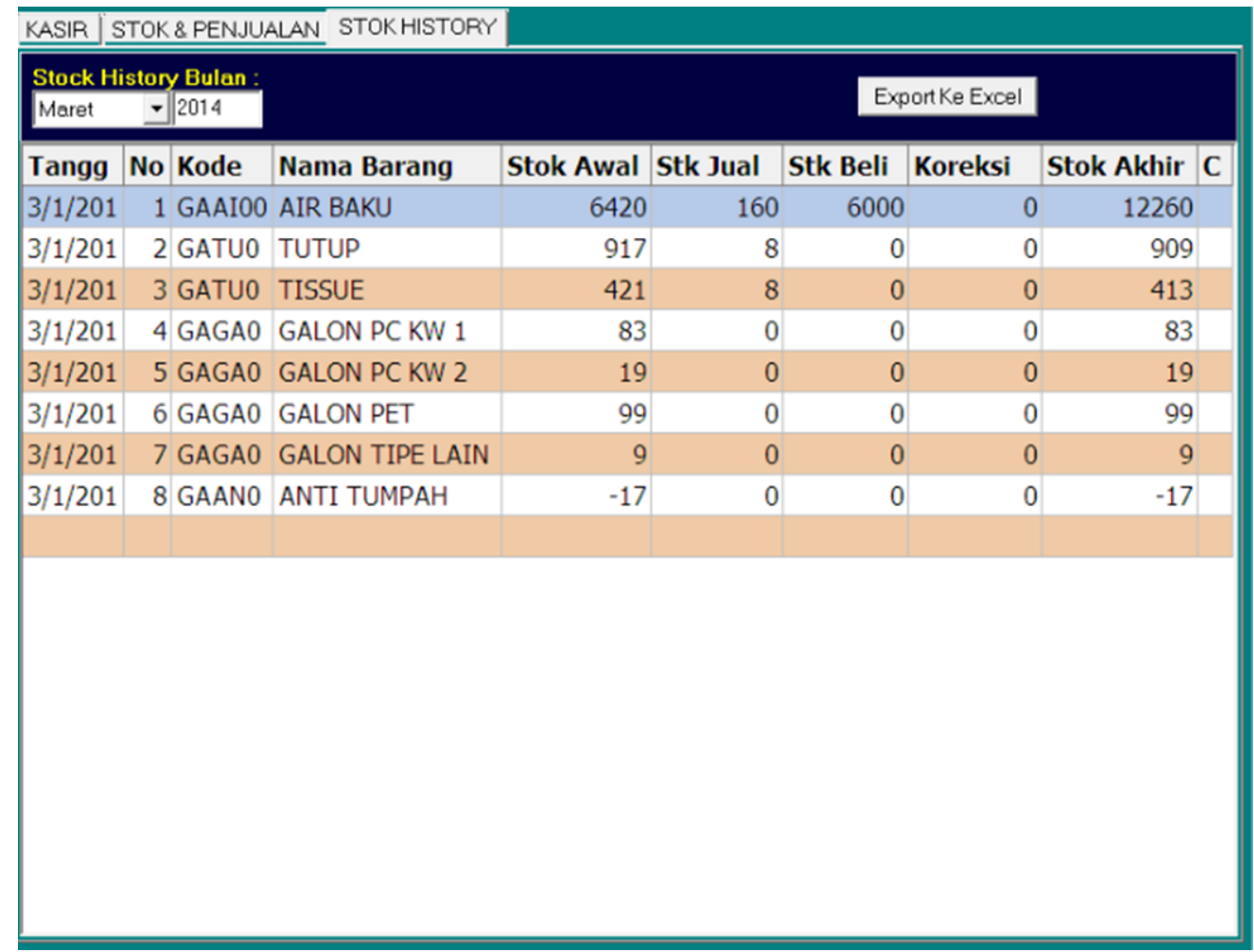

Sumber: http://beningsoft.com

Gambar 7. Contoh Aplikasi Pengelolaan Air Bersih 
Adapun ruang lingkup aplikasi yang dibuat adalah sebagai berikut:

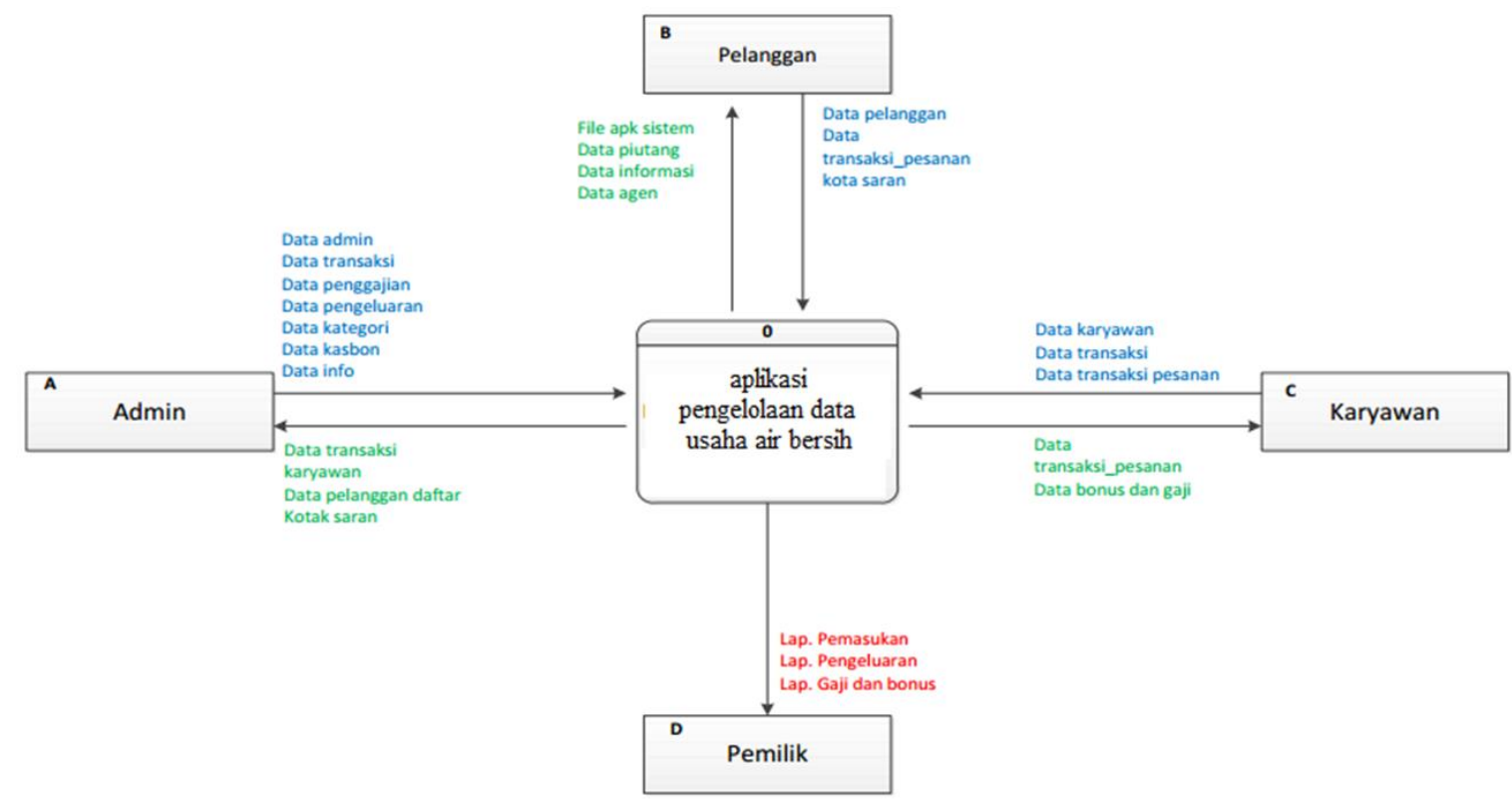

Sumber: Andi Muh. Lukman (Fak. Teknik UPRI)

Gambar 8. Ruang Lingkup Aplikasi

Adapun spesifikasi perangkat yang dibutuhkan untuk dapat mengimplementasikan perangkat teknologi informasi berupa aplikasi pengelolaan air besih adalah sebagai berikut:

Tabel 2. Spesifikasi Perangkat

\begin{tabular}{|l|l|}
\hline Nama Perangkat & Kuantitas \\
\hline Komputer Personal (PC) & 1 \\
\hline Canon Pixma E400 & 1 \\
\hline Windows OS & 1 \\
\hline Modem 3G & 1 \\
\hline $\begin{array}{l}\text { Paket XAMPP (Apache, } \\
\text { PHP, MySQL) }\end{array}$ & 1 \\
\hline
\end{tabular}

\section{KESIMPULAN} berikut:

Adapun kesimpulan dari kegiatan pengabdian masyarakat yang telah dilakukan adalah sebagai

1. Kegiatan terlaksana sesuai dengan tujuan dan rencana.

2. Kegiatan ini mendapat sambutan yang baik dari para pekerja Usaha Air Bersih di Kelurahan Muara Dua Kota Prabumulih.

3. Kegiatan ini memperluas pemahaman dalam pengolahan data pada Usaha Air Bersih di Kelurahan Muara Dua Kota Prabumulih.

4. Kegiatan seperti ini hendaknya dapat dilakukan pada jenis usaha lain, khususnya yang memiliki kerumitan didalam pengolahan data.

5. Hasil kegiatan ini masih perlu dikembangkan lagi agar pengoperasian aplikasi pengolahan data dapat dimanfaatkan dengan maksimal. 


\section{UCAPAN TERIMA KASIH}

Kami ingin mengucapkan terima kasih kepada LP2MK Universitas Indo Global Mandiri dan Pemilik Usaha Air Bersih di Kelurahan Muara Dua, Kota Prabumulih.

\section{DAFTAR PUSTAKA}

Gustriansyah.G, Sensuse.D.I, Ramadhan.A, "Decision support system for inventory management in pharmacy using fuzzy analytic hierarchy process and sequential pattern analysis approach," 3rd International Conference on New Media (CONMEDIA), Tangerang, pp. 1-6, November 2015.

Gustriansyah.R, " Sistem Pendukung Keputusan Pemilihan Dosen Berprestasi Dengan Metode ANP dan TOPSIS, " Sentika, Yogyakarta, 2016.

Sanmorino. A, "Development of computer assisted instruction (cai) for compiler model: The simulation of stack on code generation," International Conference on Green and Ubiquitous Technology (GUT), Jakarta, pp. 121-123, July 2012.

Sanmorino.A, "Clustering Batik Images using Fuzzy C-Means Algorithm Based on Log-Average Luminance," Computer Engineering and Applications, Vol. 1, No. 1, June 2012.

Sanmorino.A, Isabella, "Diagram Aliran Data dan Konsep Basis Data Sistem Informasi Manajemen Peternakan Broiler," Jurnal Ilmiah Informatika Global, Vol. 8 No. 1, Juli 2017.

Sanmorino.A, Yazid.S, "A survey for handwritten signature verification," 2012 2nd International Conference on Uncertainty Reasoning and Knowledge Engineering (URKE), Jakarta, Indonesia, pp. 54-57, 2012.

Sanmorino.A, Yazid.S, "DDoS Attack Detection Method and Mitigation Using Pattern of the Flow," IEEE International Conference of Information and Communication Technology, 2013.

Suhartanto.H, "Model Pemroses Bahasa Pemrograman Dengan tools berbasis Java, " Fakultas Ilmu Komputer Universitas Indonesia, 2012. 